\title{
AN EFFICIENT APPROACH FOR SQUARED CREST FACTOR REDUCTION IN OFDM SYSTEMS USING TONE RESERVATION WITH CUSTOMIZED CONVEX OPTIMIZATION
}

\author{
V.Kiruthika ${ }^{1}$, V.Nandalal ${ }^{2}$ \\ ${ }^{I} P G$ Scholar, Electronics and Communication Engineering, Sri Krishna College of Engineering and Technology, \\ Tamilnadu, India \\ ${ }^{2}$ Assistant Professor, Electronics and Communication Engineering, Sri Krishna College of Engineering and \\ Technology, Tamilnadu, India
}

\begin{abstract}
Orthogonal frequency-division multiplexing (OFDM) is a method of encoding digital data on multiple carrier frequencies. This scheme uses a number of sub-carriers and converts a frequency selective fading channel to a set of parallel flat fading channels. The OFDM signal is having a drawback that some signal values can be much higher than the average value. This results in high Squared Crest Factor (SCF). This paper deal with the Tone Reservation (TR) technique for reducing SCF. In this scheme few subcarriers are reserved to reduce the peak signal. These reserved carriers are called as Peak Reduction Carriers (PRCs) and these PRCs are used to reduce the SCF of the original signal. Similarly the Bit Error Rate also gets lowered. In contrast to previous methods, the TR method with Customized Convex Optimization implies a very quick convergence of minimum SCF and the bit error rate solution at a lower computational cost. The proposed method is compared with the SCF reduction techniques like Differential Scaling. The proposed OFDM system also discusses about the effects of oversampling at different rates.
\end{abstract}

Keywords: Convex Optimization, Orthogonal Frequency Division Multiplexing (OFDM), Squared Crest Factor (SCF), Tone Reservation (TR), Peak Reduction Carriers (PRCs), Complementary Cumulative Distribution Function $(C C D F)$.

\section{INTRODUCTION}

Orthogonal frequency Division Multiplexing is a technique in which high speed data is split into low speed parallel channels. One of the main practical issues of OFDM is the high Squared Crest Factor of the transmit signal. There are many techniques for reducing the SCF but these techniques either need side information or not needed. Depending on the necessity of side information the SCF reduction technique can be classified into two groups. The main two techniques which need side information is the Partial Transmit Sequence (PTS) [1], [10] and the Selected Mapping (SLM) [2], [9] technique. These techniques modify the symbols of both frequency domain and time domain. The side information is generally used for preventing the OFDM system from burst errors. The other techniques which do not need side information include Clipping and Filtering (CF) [3], Peak Windowing (PW) [4], Active Constellation Extension (ACE) [5], and Tone Reservation [6], [7]. The TR method reserves a minimum number of tones and assigns appropriate values to reduce SCF. The TR approach is also an iterative one, but it does not change the data symbols.

\section{TONE RESERVATION}

In the TR approach, a small number of unused subcarriers are reserved by the transmitter for SCF control. These unused subcarriers are known as Peak Reduction Carriers (PRCs) which are designed to be orthogonal with the data bearing subcarriers thereby causing no distortion. At the receiver side the contents of the PRCs will be ignored since it does not contain any useful information and also no side information needs to be transmitted. In general, there are two schemes to reduce the SCF in the TR technique. The first is to select the PRC set for reducing the SCF and the second is to design the proper values on these PRCs to generate an optimal peak-canceling signal that minimizes the SCF of a transmitted OFDM signal. Several methods [11-13] have been proposed to search a nearly-optimal PRC sets in the TR technique for the improvement of the SCF performance of OFDM signals.

\section{DIFFERENTIAL SCALING}

Differential Scaling is another technique which is used for the reduction of SCF. In this technique different amplitude levels are scaled in a different manner and so it is called as Differential Scaling. We have considered three types of scaling as described below. 


\subsection{Scale Up}

In this method, the amplitude levels of the average signal are increased or scaled up by a factor of $\mathrm{x}$. In this technique only the average signal gets increased, but there is no change in the peak value. The resulting Squared Crest Factor gets reduced. The reduction function for Squared Crest Factor can be shown as

$$
\begin{aligned}
h(x) & =\alpha x_{p}, & & \text { if } x>\alpha x_{p} \\
& =\beta x, & & \text { if } x<A \\
& =x, & & \text { if } A \leq x \leq \alpha x_{p}
\end{aligned}
$$

Where $x_{p}$ be the peak amplitude value which decides the clipping threshold in terms of peak value percentage and $\alpha$ denotes the scaling factor for the range $\left[\mathrm{A}, \alpha \mathrm{x}_{\mathrm{p}}\right]$ whose value is greater than one.

\subsection{Scale Down}

In this method, the higher amplitude levels of the average signal are decreased or scaled down by a factor of $\mathrm{x}$. This leads to decrease in both peak value and the average value. The resulting Squared Crest Factor gets reduced. The decrease in average power is lesser than the decrease in the peak power. The reduction function for Squared Crest Factor can be shown as

$$
\begin{aligned}
h(x) & =\alpha x_{p}, & & \text { if } x>\alpha x_{p} \\
& =\gamma x, & & \text { if } B \leq x \leq \alpha x_{p} \\
& =x, & & \text { if } x<B
\end{aligned}
$$

Where $x_{p}$ be the peak amplitude value which decides the clipping threshold in terms of peak value percentage and $\alpha$ denotes the scaling factor for the range $\left[\mathrm{B}, \alpha \mathrm{x}_{\mathrm{p}}\right]$ whose value is lesser than one.

\subsection{Scale Up and Down}

This method deals with the combination of both Scale Up and Scale Down approach. When compared with the above two approaches this approach gives more reduction in Squared Crest Factor since this method carries the advantages of both Scale Up and Scale Down. The reduction function for Squared Crest Factor can be shown as

$$
\begin{aligned}
h(x) & =\alpha x_{p}, & & \text { if } x>\alpha x_{p} \\
& =\gamma x, & & \text { if } B \leq x \leq \alpha x_{p} \\
& =\beta x, & & \text { if } x<A \\
& =x, & & \text { if } A \leq x \leq B
\end{aligned}
$$

Where $x_{p}$ be the peak amplitude value which decides the clipping threshold in terms of peak value percentage, $\alpha$ denotes the scaling factor in the range $[0, \mathrm{~A})$ and $\beta$ is the scaling factor for the range $\left[\mathrm{B}, \alpha \mathrm{x}_{\mathrm{p}}\right]$. A marker is used for making all the scaling techniques realizable. This marker is used for identifying the inversion sequence at the receiver. The marker may be accommodated like the pilot symbols or transmitted on different frequencies orthogonal to the carrier signal.

\section{TONE RESERVATION WITH CUSTOMIZED CONVEX OPTIMIZATION}

The OFDM signal is generated and the QPSK modulation is performed. IFFT converts the frequency domain information back to the time domain and the Tone Reservation technique is applied. Then again the information is converted back into frequency domain using FFT. The signal is demodulated so that the original signal is obtained and the CCDF characteristics are plotted. The process flow diagram for the Tone Reservation technique is given below.

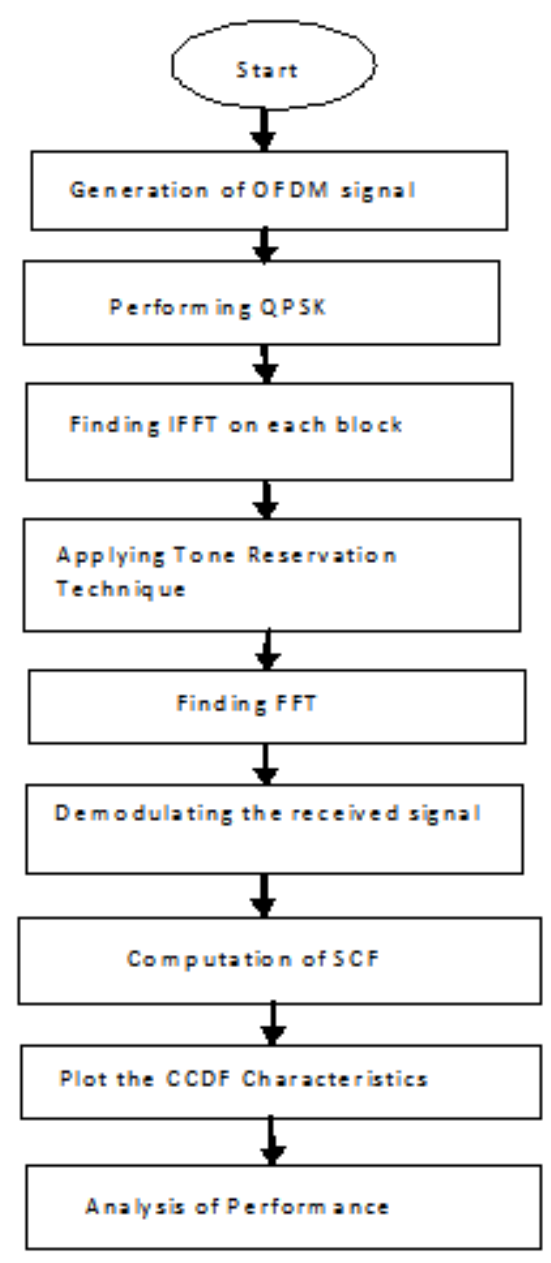

Fig -1: Flowchart for TR Technique

\subsection{Customized Convex Optimization}

Convex minimization, a subfield of optimization, studies the problem of minimizing convex functions over convex sets. Convex Optimization [8] is used widely in the estimation of signals, communication and networking and for designing electronic circuits.

Condition for convexity:

$$
f(a x+b y) \leq a f(x)+b f(y)
$$


General form of optimization problem

$$
\begin{array}{ll}
\text { Minimize } f(x) & \text { (objective function) } \\
\text { Subject to } g(x) \leq b & \text { (constraint function) }
\end{array}
$$

Where $\mathrm{x}$ is the optimization variable for both objective and constraint function. The SCF problem is treated as a convex optimization problem so that minimum SCF is obtained.

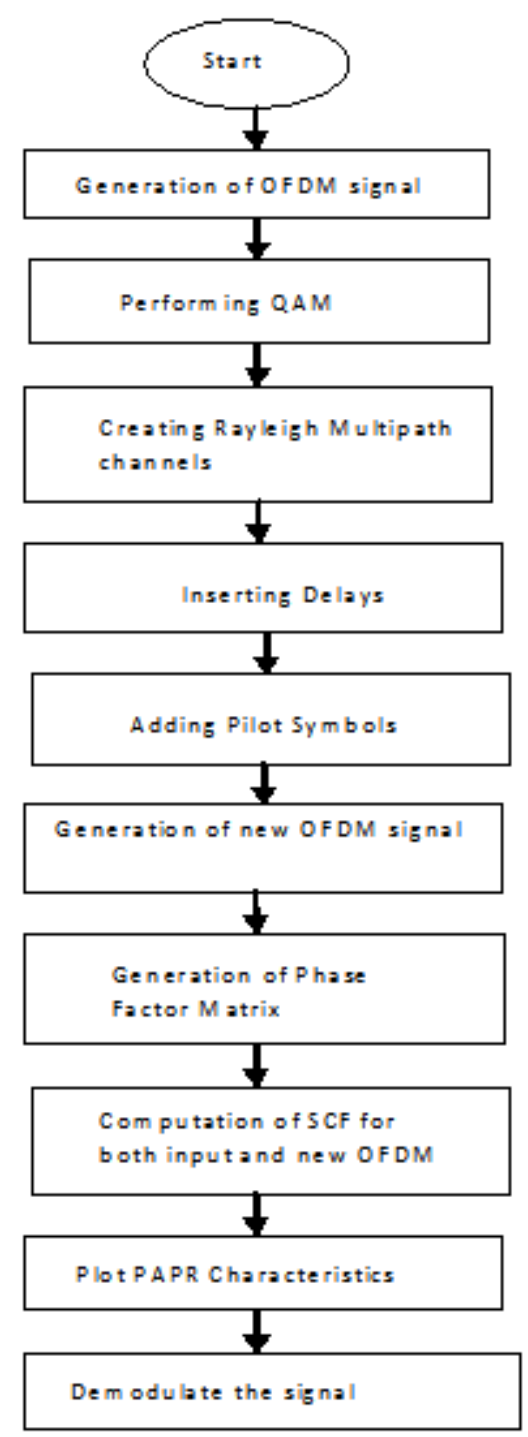

Fig -2: Flowchart for Convex Optimization

The above flowchart represents the step involved in convex optimization. The OFDM signal contains 48 data symbols, 4 pilot symbols and 12 reserved tones and 128 symbols. The length of the Cyclic Prefix is 16. The subcarriers (data/pilot) were modulated using 16-quadrature amplitude modulation (QAM).The data is divided into many orthogonal data streams and each was passed to a separate subcarrier. By performing IFFT the frequency domain symbols are transformed to time domain. Then demodulation is performed and the original signal is received by the receiver. For Customized convex optimization instead of generating a new signal the tone reserved signal is given as input and the SCF characteristics are obtained.

\section{SIMULATION RESULTS}

Simulation and analysis of the proposed method are carried out for 128 sub-carrier OFDM system with QPSK modulation scheme.

The figures 3 and 4 shown below shows the generation of OFDM signals with 128 sub carriers and the QPSK modulation for the generated signal respectively.

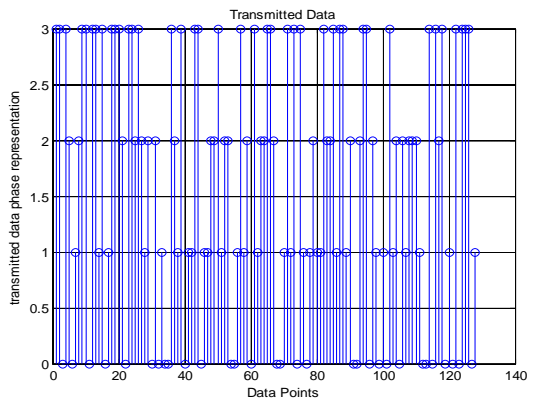

Fig -3:Transmitted data phase representation

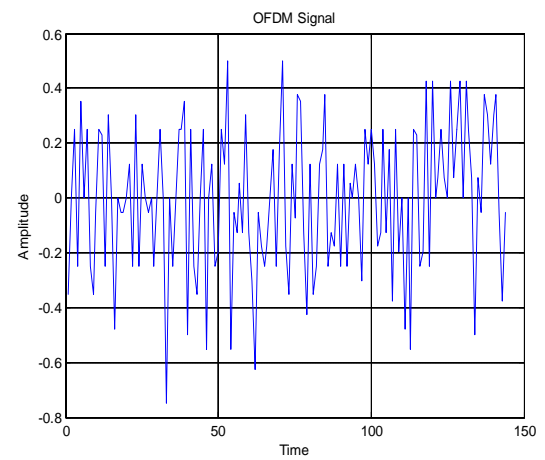

Fig -4:Transmitted OFDM Signal

Figure 5 shown below describes the CCDF vs SCF plot for Tone Reservation and Differential Scaling technique. The performance of Squared Crest Factor (SCF) is better in Differential Scaling when compared to Tone Reservation.

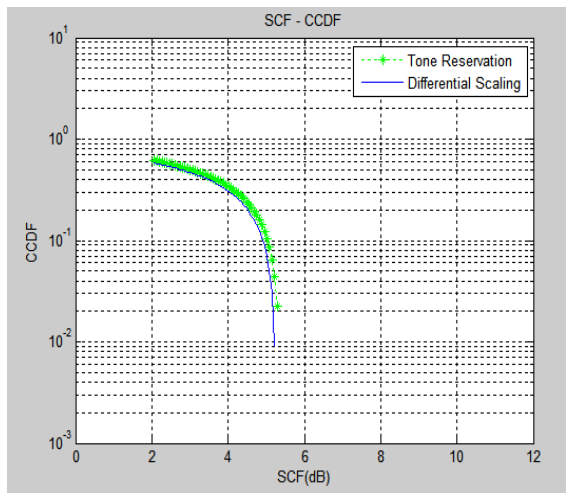

Fig -5:CCDF vs. Squared Crest Factor 
Table -1: SCF performance for different sampling rate and different subcarriers

\begin{tabular}{|c|c|c|}
\hline $\begin{array}{l}\text { Sampling } \\
\text { Rate }\end{array}$ & $\begin{array}{ll}\text { Number } & \text { of } \\
\text { Subcarriers } & \end{array}$ & $\mathrm{SCF}(\mathrm{dB})$ \\
\hline \multirow[t]{2}{*}{$\mathrm{L}=2$} & 128 & 3.984 \\
\hline & 256 & 4.342 \\
\hline \multirow[t]{2}{*}{$\mathrm{L}=4$} & 128 & 4.01 \\
\hline & 256 & 4.346 \\
\hline \multirow[t]{2}{*}{$\mathrm{L}=8$} & 128 & 4.019 \\
\hline & 256 & 4.363 \\
\hline
\end{tabular}

The below figure represents a general OFDM signal with and without optimization.

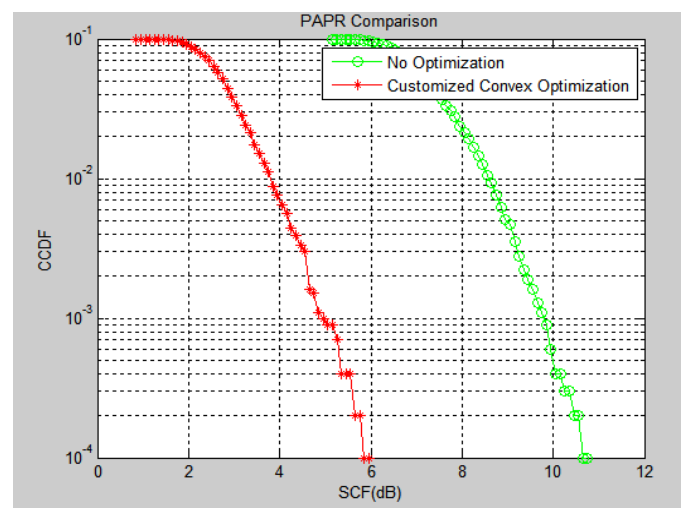

Fig -6: OFDM signal with and without Optimization

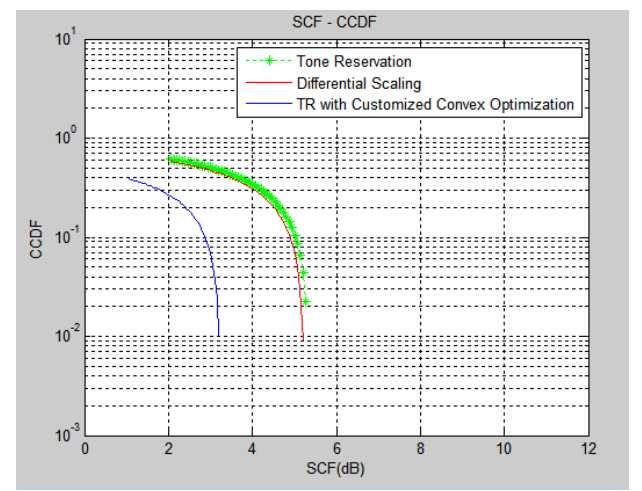

Fig -7: SCF Performance with Convex

Optimized TR, TR without optimization and Differential Scaling

From the figure 6, it is clear that the SCF is reduced while applying customized convex optimization. The SCF is about 10.9 when no optimization is applied and if optimization technique is applied, it reduces to 5.7. So there will be a reduction of $5.2 \mathrm{~dB}$ the optimization technique is applied. From the figure 7 it is clear that after applying customized convex optimization the SCF gets reduced more in the tone reservation technique when compared with Differential Scaling technique. The below table shows the SCF performance for Differential Scaling and Tone Reservation with and without optimization.

Table -2: SCF performance

\begin{tabular}{|l|l|l|l|}
\hline \multirow{2}{*}{ CCDF } & \multicolumn{3}{|l|}{$\mathrm{SCF}(\mathrm{dB})$} \\
\cline { 2 - 4 } & $\begin{array}{l}\text { Differential } \\
\text { Scaling }\end{array}$ & $\begin{array}{l}\text { Tone } \\
\text { Reservation } \\
\text { without } \\
\text { Optimization }\end{array}$ & $\begin{array}{l}\text { Tone } \\
\text { Reservation } \\
\text { with } \\
\text { Optimization }\end{array}$ \\
\hline 0.3 & 2.7 & 3.02 & 1.8 \\
\hline 0.25 & 3.0 & 3.29 & 2.08 \\
\hline 0.2 & 3.4 & 3.5 & 2.22 \\
\hline 0.15 & 3.65 & 3.8 & 2.54 \\
\hline 0.1 & 3.84 & 3.97 & 2.83 \\
\hline 0.05 & 3.98 & 4.15 & 3.06 \\
\hline 0 & 4.19 & 4.29 & 3.20 \\
\hline
\end{tabular}

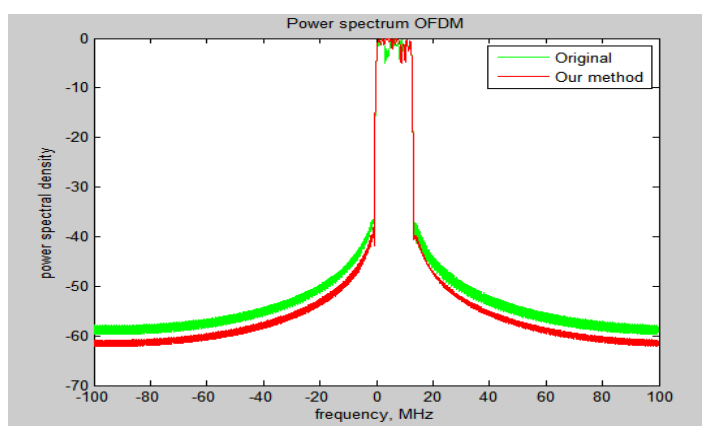

Fig -8: PSD plot for the proposed technique

From the Figure 8, the Power Spectral Density is reduced in TR technique with respect to Frequency. This shows that the Out of band radiation is minimized in TR Technique.

Table -3: Out of band radiation comparison chart

\begin{tabular}{|c|c|c|c|c|}
\hline \multicolumn{2}{|c|}{$\begin{array}{l}\text { Performance } \\
\text { Measure }\end{array}$} & $\begin{array}{l}\text { Normalize } \\
\mathrm{d} \\
\text { Frequency }\end{array}$ & $\begin{array}{l}\text { Normalize } \\
\mathrm{d} \\
\text { Frequency }\end{array}$ & $\begin{array}{l}\text { Normalize } \\
\mathrm{d} \\
\text { Frequency }\end{array}$ \\
\hline \multirow{2}{*}{$\mathrm{L}=1$} & $\begin{array}{l}\text { Without } \\
\text { TR } \\
\text { Techniqu } \\
\text { e }\end{array}$ & $\begin{array}{l}-0.2499 \\
\mathrm{~dB}\end{array}$ & $\begin{array}{l}-0.4758 \\
d B\end{array}$ & $\begin{array}{l}-0.8984 \\
\mathrm{~dB}\end{array}$ \\
\hline & $\begin{array}{l}\text { With TR } \\
\text { Techniqu } \\
\text { e }\end{array}$ & $-1.328 \mathrm{~dB}$ & $-3.374 \mathrm{~dB}$ & $-3.262 \mathrm{~dB}$ \\
\hline \multicolumn{2}{|c|}{ Reduction } & $1.0781 \mathrm{~dB}$ & $2.8982 \mathrm{~dB}$ & $2.3636 \mathrm{~dB}$ \\
\hline \multirow[t]{2}{*}{$\mathrm{L}=2$} & $\begin{array}{l}\text { Without } \\
\text { TR } \\
\text { Techniqu } \\
\text { e }\end{array}$ & $\begin{array}{l}-0.4945 \\
d B\end{array}$ & $\begin{array}{l}-0.8571 \\
d B\end{array}$ & $\begin{array}{l}-1.215 \mathrm{~dB} \\
-1.215 \mathrm{~dB}\end{array}$ \\
\hline & $\begin{array}{l}\text { With TR } \\
\text { Techniqu } \\
\text { e }\end{array}$ & $-3.721 \mathrm{~dB}$ & $-4.758 \mathrm{~dB}$ & $-5.323 \mathrm{~dB}$ \\
\hline
\end{tabular}




\begin{tabular}{|c|c|c|c|c|}
\hline \multicolumn{2}{|c|}{ Reduction } & $3.23 \mathrm{~dB}$ & $3.900 \mathrm{~dB}$ & $4.108 \mathrm{~dB}$ \\
\hline \multirow{2}{*}{$\mathrm{L}=4$} & $\begin{array}{l}\text { Without } \\
\text { TR } \\
\text { Techniqu } \\
\mathrm{e}\end{array}$ & $\begin{array}{l}-0.6423 \\
\mathrm{~dB}\end{array}$ & $-0.948 \mathrm{~dB}$ & $-1.435 \mathrm{~dB}$ \\
\hline & $\begin{array}{l}\text { With TR } \\
\text { Techniqu } \\
\text { e }\end{array}$ & $-5.031 \mathrm{~dB}$ & $-5.343 \mathrm{~dB}$ & $-6.568 \mathrm{~dB}$ \\
\hline \multicolumn{2}{|c|}{ Reduction } & $4.3887 \mathrm{~dB}$ & $4.395 \mathrm{~dB}$ & $5.133 \mathrm{~dB}$ \\
\hline \multirow[t]{2}{*}{$\mathrm{L}=8$} & $\begin{array}{l}\text { Without } \\
\text { TR } \\
\text { Techniqu } \\
\text { e }\end{array}$ & $\overline{-} .7342 \mathrm{~dB}$ & $\begin{array}{l}-0.9367 \\
\mathrm{~dB}\end{array}$ & $\begin{array}{l}-1.2312 \\
\mathrm{~dB}\end{array}$ \\
\hline & $\begin{array}{l}\text { With TR } \\
\text { Techniqu } \\
\mathrm{e}\end{array}$ & $-6.451 \mathrm{~dB}$ & $-7.532 \mathrm{~dB}$ & $\begin{array}{l}-8.6985 \\
d B\end{array}$ \\
\hline \multicolumn{2}{|l|}{ Redi } & $5.7168 \mathrm{~dB}$ & $6.595 \mathrm{~dB}$ & $7.4673 \mathrm{~dB}$ \\
\hline
\end{tabular}

\section{CONCLUSIONS}

The proposed Tone Reservation technique changes the response of the filter and hence produces a better reduction in SCF. The SCF reduction is achieved more while applying Customized Convex Optimization. Simulation results clearly show that this method offers less distortion in the processed OFDM symbols with better out-of band radiation. The algorithm was defined for QPSK but it equally applies for other modulation techniques as well.

\section{ACKNOWLEDGEMENTS}

Our thanks to the experts who have contributed towards the development of this paper.

\section{REFERENCES}

[1]. Seung Hee Han and Jae Hong Lee, "Reduction of PAPR of an OFDM Signal by Partial Transmit Sequence Technique with Reduced Complexity", IEEE Global Telecom. Conference, GLOBECOM 2003.

[2]. H. Breiling, S. H. Müller-Weinfurtner, and J.B.Huber, "SLM peak power reduction without explicit side information," IEEECommun.Lett., vol. 5, no. 6, pp. 239241, Jun. 2001.

[3]. S.-K. Deng and M.-C. Lin, "Recursive clipping and filtering with bounded distortion for PAPR reduction," IEEE Trans. Commun., vol.55, no. 1, pp. 227-230, Jan. 2007.

[4]. M. Ojima and T. Hattori, "PAPR reduction method using clipping and peak-windowing in CI/OFDM system," in Proc. IEEE Veh. Technol.Conf, pp. 1356-1360., 2007.

[5]. D. L. Jones, "Peak power reduction in OFDM and DMT via active channel modification," in Proc. IEEE Asilomar Conf. Signals, Syst.,Comput., pp. 1076-1079, 1999.

[6]. S. Janaaththanan, C. Kasparis, and B. G. Evans, "A gradient based algorithm for PAPR reduction of OFDM using tone reservation technique,"in Proc. IEEE Veh. Technol. Conf., pp. 2977-2980, 2008.
[7]. S. Hosokawa, S. Ohno, K. A. D. Teo, and T. Hinamoto, "Pilot tone design for peak-to-average power ratio reduction in OFDM," in Proc.IEEE Int. Symp. Circuits Syst, pp. 6014-6017, 2005.

[8]. Aggarwal and T. Meng, Minimizing the peak-to average power ratio of OFDM signals using convex optimization, in IEEE Trans. Signal Process. Vol. 54, no. 8, pp. 30993110, 2006.

[9]. R. Bauml, R. Fischer, and J.Huber, Reducing the peak-to-average power ratio of multicarrier modulation by selected mapping, Linear Algebra Appl., 162 (1992), to appear.

[10]. L. Cimini Jr. and N. Sollenberger, Peak- to- average Power ratio reduction of an OFDM signal using Partial transmit sequences, IEEECommun. Lett. Vol. 4, no. 3, pp. 8688, 2000.

[11]. D. W. Lim, H.-S. Noh, J.-S. No, and D.-J. Shin, "Near optimal PRT set selection algorithm for tone reservation in OFDM systems," IEEE Trans. Broadcast., Vol. 54, no. 3, pp. 454-460, Sept. 2008.

[12]. J.-C. Chen and C.-P. Li, "Tone reservation using nearoptimal peak reduction tone set selection algorithm for PAPR reduction in OFDM systems," IEEE Signal Process. Lett., Vol. 17, no. 11, pp. 933-936, Nov.2010.

[13]. J. Tellado, "Peak to average power reduction for multicarrier modulation,"Ph.D. dissertation, Stanford University, 2000

\section{BIOGRAPHIES}

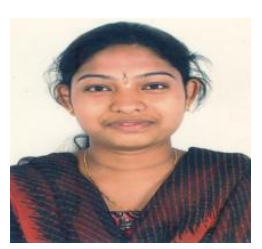

V.Kiruthika received her B.E degree in Electronics and Communication Engineering in Annamalai University, Chidambaram, India and currently pursuing M.E degree in Sri Krishna College of Engineering and Technology, Coimbatore, India. Her research interests include Wireless Networks, Image Processing and Antenna and Wave Propagation

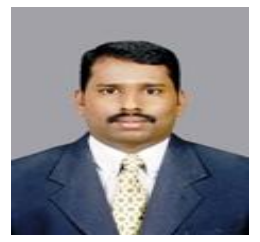

V.Nandalal received his M.E degree in Anna University, Chennai, India. Currently he is working as an Assistant Professor in Sri Krishna College of Engineering and Technology, Coimbatore, India. His current research interests include Wireless Communication, Antenna and Wave Propagation, Microwave System 